\title{
Parasitic burden in Red panda (Ailurus fulgens Cuvier, 1825) of Illam district Community forest, Nepal.
}

\author{
Sajan Shrestha and Mahendra Maharjan \\ Central Department of Zoology, Tribhuvan University, Kirtipur, Kathmandu, Nepal \\ For correspondence: mmaharjan@cdztu.edu.np
}

\begin{abstract}
Parasitic diseases pose significant conservation threat in conservation of Red panda. In order to assess the parasitic burden in Red panda of Illam district, Nepal, 14 faecal samples were aseptically collected from community forest of Illam using line transect method following the GPS location. The samples were examined using standard concentration techniques. All the collected samples were found to be positive for both protozoan and helminth parasites. The recorded protozoan parasites includes Eimeria sp., Entamoeba sp., and Balantidium sp. with $64.28 \%, 57.14 \%$ and $14.28 \%$ proportion respectively. Similarly the proportion of seven helmithes parasites revealed Oxyuris (100\%), Baylisascaris (57.14\%), Trichostrongylus (50\%), Strongyloides (50\%), Trichuris (42.8\%), Crenosoma (42.85\%) and Hookworm (35.7\%). The most of the samples (78.52\%) revealed either multiple parasitic infection or triple infection (21.42\%) with low to moderate intensity of infection. In conclusion, The parasitic burden in Red Pandas of Illam, community forest is very high hence urgently needs to address this threat in Red panda conservation action plan.
\end{abstract}

\section{Introduction}

The Red Panda (Ailurus fulgens Cuvier, 1825) is the one living species of family aeluridae (Shrestha 2015) and commonly called Cat bear, Panda bear, Lesser Panda etc. There are two sub species of the genera that is Ailurus fulgens fulgens and Ailurus fulgens styani. Ailurus fulgens fulgens is smaller and lighter than Ailurus fulgens styani. Red Panda is an endemic sepsis of Himalayan mountain region (Roberts and Gittleman 1984) which threatened with extinction worldwide (Wang et al. 2008). It inhabits in the temperate zone at low temperatures (Yonzon 1989) in the countries of the Himalayan Mountain Range which includes Nepal, India, Bhutan, Myanmar and China (Roberts and Gittleman 1984).

The Red Panda resides in evergreen, deciduous, and mixed forests with dense bamboo covered (Roberts and Gittleman 1984, Wei et al. 1999, Choudhury 2001, Pradhan et al. 2001). Despite being a member of the order Carnivora, Red Panda is a specialized herbivore with a low nutrient diet. More than $86 \%$ of its diet includes ringal bamboo (Pradhan et al. 2001, Yonzon \& Hunter 1991), which has forced the animal to inhabit in narrow range of forest types and restricted geographic area (Yonzon 1989, Choudhury 2001, Pradhan et al. 2001b, Sharma and Belant 2009). Because of the specialized diet and narrow range of habitat, Red Panda has been considered as an indicator species of ecosystem health in eastern Himalayan broadleaved and conifer forests (Yonzon et al. 2000).

Red Panda was classifies as vulnerable status by IUCN, that suggest a likely extinction globally if conservation measures are not initiated soon (Wang et al. 2008) and by Convention on International Trade

Nepalese Journal of Zoology | Online Volume 3 Issue 1 | November 2015 | Page 49 
in Endangered Species of Wild Fauna and Flora (CITES) in its Appendix I (species threatened with extinction which are or may be affected by trade). In the persent days, the population of Red Pandas are declining day by day and occurs with a patchy distribution due to habitat fragmentation, loss of foraging habitat, human and livestock disturbances, poaching, and disease (Yonzon and Hunter 1991b, Wei et al. 1999, Choudhury 2001, Patterson-Kane et al. 2009, Sharma and Belant 2009, Dorji et al. 2012, Sharma et al. 2014). Parasitic diseases is posing still neglected but significant conservation threat of Red panda (Zhang et al. 2007, Thomas 2002) worldwide including Nepal. The most of the Parasitic infection negatively impact on body weight gain, quality of reproduction due to loss of appetite, nutrient uptake and utilization (Gross et al. 1999) and even death (Rao and Acharjyo 1984, Hansen and Perry 1994). Since the Red panda population is very less and in declining trend in Illam community forest, the present study was designed to assess the parasitic burden in Red panda.

\section{Materials and Methods}

The study was carried out at Maimajhuwa, Mabu, Jamuna and Jogmai VDCs of Illam. It was designed to cover all the Red Pandas habitat of the community forest of Illam. Using GIS system line transect grids were selected from the elevation ranged $2200-4800 \mathrm{~m}$ with the grid size $1.7 \times 1.7(2.89) \mathrm{Km}^{2}$ while in each grid two transects were made. First transect was $500 \mathrm{~m}$ apart from starting point of grid and second transect was $700 \mathrm{~m}$ apart from first transect. Samples were collected from transects and also by opportunistically from the study area. Altogether 14 faecal samples were collected from the study area and preserved in $2.5 \%$ Potassium dicromate. The faecal samples were examined in the laboratory of CDZ by both direct smear and concentration methods (floatation and sedimentation) for detection of intestinal parasites as well as stoll's count for intensity of parasites of Red Panda. The size of the eggs, oocyst and cyst measured using oculomicrometer. The identification of the parasitic oocyst, cyst, egg and larva were done on the basis of shape and size along with published literature (Barutzki and Schaper 2009, Bhir 1998, Villeneure 2013, Brianti et al. 2012).

\section{Results}

All the samples of Red Panda collected from study area were found positive for parasitic infection. From the examination 10 different genera of parasites (Three protozoan and seven helminth) were observed. Among the protozoan parasites coccidian; Eimeria sp. showed the highest prevalence (64.28\%) followed by Entamoeba sp. (57.14\%) and Balantidium sp. (14.28\%). Study revealed the existence of several species of coccidian parasites, which were grouped into two broad groups; Eimeria with micropyle and without micropyle. The Red Panda were found to be almost equally infected with both groups of this parasites (Table: 1).

Table 1. Prevalence of Protozoan parasite of Red Panda from Illam community forest

\begin{tabular}{|l|l|l|l|}
\hline S.N & Class & Name of Parasite & Prevalence Rate (\%) \\
\hline 1. & Sarcodina & Entamoeba sp. & $8(57.14 \%)$ \\
\hline 2. & Sporozoa & Eimeria with micropyle & $9(64.28 \%)$ \\
\cline { 3 - 4 } & & Eimeria without micropyle & $8(57.14 \%)$ \\
\hline 3. & Litostomatea & Balantidium sp. & $2(14.28 \%)$ \\
\hline
\end{tabular}

Helminth parasites observed in the Red Panda of Illam community forest includes only nematode parasites, while cestode and trematode were not observed. Oxyuris sp. (100\%) was the most predominant parasites among the seven genera of nematode parasites followed by Baylisascaris sp. (57.14\%),

Nepalese Journal of Zoology | Online Volume 3 Issue 1 | November 2015 | Page 50 
Trichostrongylus sp. (50\%), Strongyloides sp. (50\%), Crenosoma sp. (42.85\%), Trichuris sp. (42.85\%) and Hookworm (35.71\%).

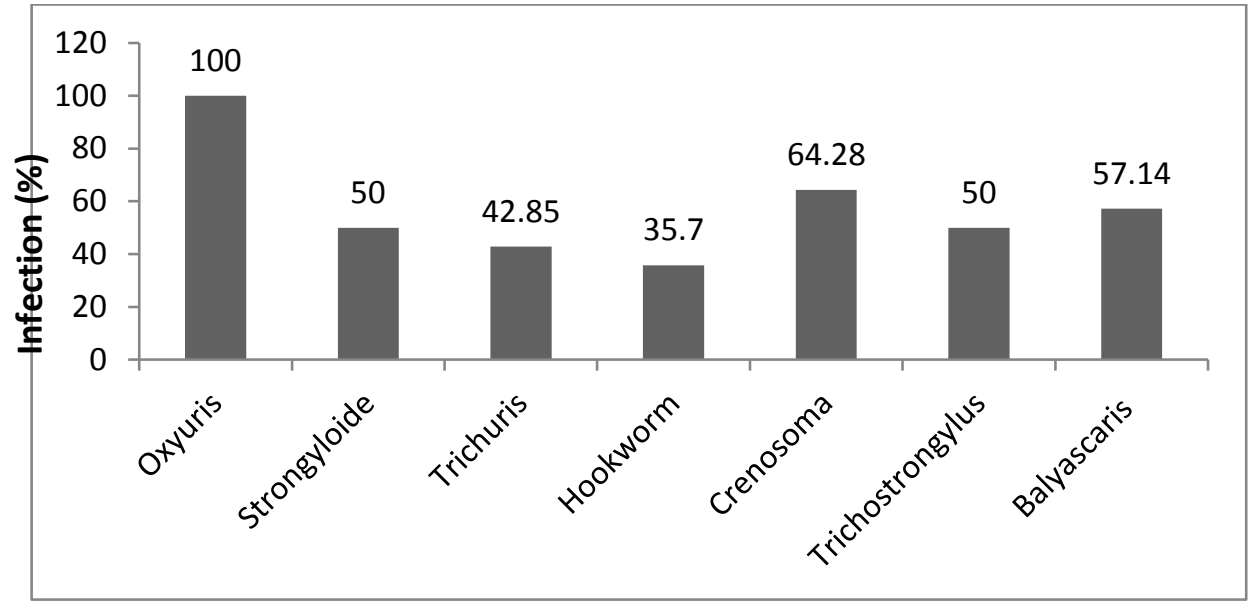

Figure 1. Prevalence of nematode in Red Panda

Out of 14 samples, $78.57 \%$ were found to be co-infected by different genera, $21.42 \%$ by triple genera while single infection and double co-infection were absent (Fig: 2).

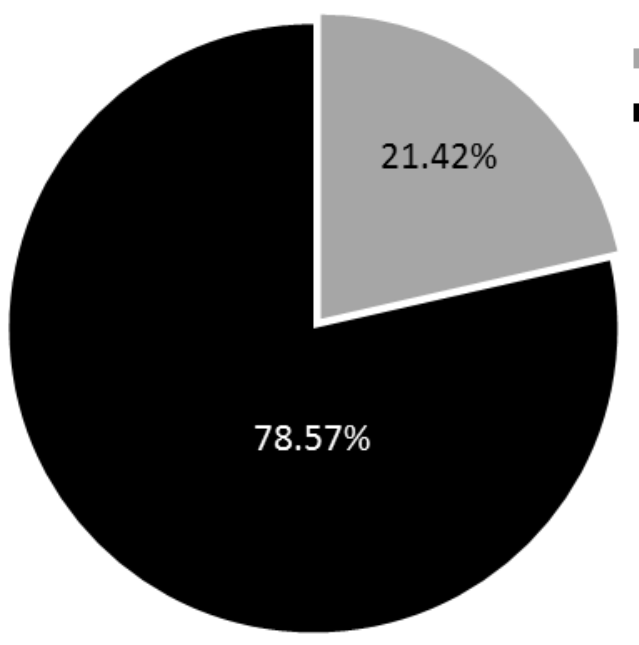

Figure 2. Mixed infection on Red panda

Heavy parasitic infection was considered in those samples which has six or more ova or oocyst observed per field. Maximum five samples of Red Panda showed heavily infected with coccidian parasite; Eimeria. While two each samples showed high intensity of Oxyuris, Trichostrongylus and Baylisascaris.

Nepalese Journal of Zoology| Online Volume 3 Issue 1 | November 2015 | Page 51 
Table 2. Intensity of infection of intestinal parasite in Red Panda

\begin{tabular}{|l|l|l|l|l|l|l|}
\hline S.N & Class & Name of Parasite & + & \multicolumn{1}{|c|}{} & $\mathbf{+ + +}$ & $\mathbf{+ + + +}$ \\
\hline 1. & Sarcodina & Entamoeba sp. & 3 & 4 & 1 & - \\
\hline 2. & \multirow{2}{*}{ Sporozoa } & Eimeria with micropyle & - & 1 & 3 & 5 \\
\cline { 3 - 7 } & & Eimeria without micropyle & 1 & 4 & 2 & - \\
\hline 3. & Litostomatea & Balantidium sp. & 2 & - & - & - \\
\hline 4. & Nematoda & Oxyuris sp. & 2 & 6 & 4 & 2 \\
\hline 5. & & Strongyloides sp. & 4 & 2 & 1 & - \\
\hline 6. & & Hook worm & 2 & 2 & 1 & - \\
\hline 7. & & Crenosoma sp. & 3 & 1 & 2 & - \\
\hline 8. & & Trichostrongylus sp. & 2 & 1 & 2 & 2 \\
\hline 9. & & Baylisascaris sp. & 3 & 2 & 1 & 2 \\
\hline 10. & & Trichuris sp. & 4 & 1 & 1 & - \\
\hline
\end{tabular}

Discussion and Conclusion

Wild life disease research in Nepal is very much limited particularly in Red panda. Available data (Lama et al. 2015, Shrestha 2015) emphasized that parasitic burden is becoming a major conservation threat in Rolpa and Rara National Park, Mugu. The small number of Red panda has been found to be distributed in Community forest of Illam district. A total of 14 faecal samples of Red Panda were collected from the community forest of Illam and examined by concentration methods. All the samples (100\%) were found to be positive for both protozoan and helminthes parasites. This prevalence rate of Red Panda was almost similar as compared to 93.02\% reported in Red panda from Rara National Park (RNP) (Shrestha 2015) and $100 \%$ in Kothi Bhir community area (KBCA), Rolpa (Lama et al. 2015). But higher than the reports of Bartelsen et al. (2010) and Pradhan et al. (2011) which showed 35\% and 46.66\% parasitic infection from European zoo and Darjeeling, India respectively.

From the economic and sanitary point of view, coccidian parasites are the most prevalent among protozoa. Eimeria is the most common coccidian parasites among wildlife and livestock. The prevalence of Eimeria with micropyle and without micropyle in Illam almost similar with Eimeria reported from RNP (Shrestha 2015). High prevalence of Eimeria infection has been also reported from Raccoons of America (Dubey et al. 2000, Wright and Gompper 2005 and Foster et al. 2004).

Besides the coccidian parasites, the Red Panda were found to be infected with two other protozoan parasites, Entamoeba sp. and Balantidium sp. Amoebic dysentery, an intestinal disease caused by infection with the protozoan parasite Entamoeba sp. is an important disease of man and animals throughout the world. Entamoeba sp. had also been reported from Red Panda of RNP (Shrestha 2015). In both RNP and Illam, Red Panda were infected with more than $50 \%$ by Entamoeba species.

Balantidium coli is the ciliate zoonotics protozoan parasites. Non-human primates have been considered the most important reservoirs for human infection (Nakauchi 1999). Balantidium sp. has been reported from different animals by Nakauchi (1999) but this is the first case to report the Balantidium sp. in Red Panda in the global context with prevalence rate $14.28 \%$. The first report on isolation and maintenance of B. coli was done by Barrett and Yarbroug (1921) in animals. B. coli are a ciliated and a normal inhabitant of intestine of wild and domestic animals, probably capable of becoming somewhat pathogenic under favorable condition. It has been identified by Varadharajan and Kandasamy (2000) from India. The

Nepalese Journal of Zoology | Online Volume 3 Issue 1 | November 2015 | Page 52 
infection of $B$. coli may be due to the contamination of water or food with cyst in the grazing area (Schuster and Ramirez 2008).

Generally wild animals become infected with nematode, cestode and trematode helminth parasites. To compared the life cycle of cestode and trematode, a suitable intermediate host is required but not for most of the nematode parasites. Interestingly, Red Panda of Illam were found infected with only nematode parasites but livestock were infected by cestode and trematode too.

However the trematode, Ogmocotyle ailuri was previously described from Red Panda at a zoo in the America (Price 1954 and 1960). O. ailuri also isolated from the small intestine of Taiwanese monkey (Macaca cyclopis) (Yoshimura et al. 1996) and Japanises monkey (Macaca fasaculata) (Iwaki et al. 2012).Another trematode, Heterobiharzia americana also recorded in Archer and Wichita countries of north contra Texa and overall prevalence was 47.2\% (Kelley 2010) and other trematodes Alaria sp., Digenea sp. and Eurytrema procyonis were observed in Raccoon (Wright and Gompper 2005). Prevalence of trematode were found $13 \%$ in Red Panda from KBCA (Lama et al. 2015) but genera was unidentified. Absent of trematodes in present study might be due to absent of suitable intermediate host in Illam. Trematode infection was most common among livestock (Bandyopadhaya et al. 2010, Yadav and Tando 1989, Byanju et al. 2011, Kanyari et al. 2009, Chouwdhary et al.1993, Pathak 2011).

Cestode infection in Red Panda (Lama et al. 2015) had shown from KBCA similarly the Red Panda of RNP have been reported to be infected with Moniezia, a common herbivore cestode parasite but none of the Red Panda samples collected from Illam were positive. However three genera of cestode had been reported from Raccoon in Archer and Wichita countries of North Central Taxas including Atrioenia procyonis, Mesocestoides spp., Taenia pisiformis (Kelley and Horner 2008).

Altogether seven genera of nematodes in Red Panda were observed from Illam community forest. Among them Oxyuris sp. showed the $100 \%$ prevalence which was highest than $58.14 \%$ recorded by Shrestha (2015). The highest prevalence rate of Oxyuris may be due to the cool climate of the area. Cool climate is suitable for the development of Oxyuris larva.

Baylisascaris is an important intestinal nematode of Red Panda as well as Raccoon. This parasite had been recorded from Spain in white-headed lemurs (Eulemur albifrons) (Martinez et al. 2015), North America (Kazacos 2001), Germany (Bauer et al. 2011). In this study the prevalence of Baylisascaris was found $57.14 \%$ which was higher than $38.88 \%$ and $13.04 \%$ prevalence rate of Baylisascaris reported in Red Panda from Rara National Park, Mugu, Nepal (Shrestha 2015) and Kothi Bhir Community area, Rolpa, Nepal (Lama et al. 2015) respectively. Baylisascaris is found in Red Panda, Gient Panda, Raccoon, Cat, Dog etc. Nematodes like, B. procyonis, Capillaris acrophili, C. plica, C. procyonis, C. putorii and Placoconus lotoris had been reported in Raccoons from Southern New York (Wright and Gompper 2005). Similarly, B. procyonis was also reported in Raccoons from Western North Carolina (Hernandez et al. 2012). The highest prevalence rate were recorded from North-Eastern, mid-western ,mid-Atlantic, some western states (California, Washington, Oregon and Coloradol and some region of Taxas (Kazacos 2001, Long et at. 2006, Chavez et al. 2012).

During the study, Trichostrongylus sp. was recorded for first time from Red Panda in the global context. The prevalence of Trichostrongylus sp. and Strongyloides sp. in Red Panda was found $41.46 \%$ and 50\% respectively. Strongyloides sp. had been recorded in Red Panda by Shrestha (2015) and prevalence was low compared to present study. The parasite was already recorded in American Raccoons from New York (Wright and Gompper 2005).

Nepalese Journal of Zoology | Online Volume 3 Issue 1 | November 2015 | Page 53 
Trichuris is another common nematode parasite prevalent in Red Panda. The parasite has been reported from RNP (Shrestha 2015) and KBCA (Lama et al. 2015). The prevalence of Trichuris was 42.85\% which was higher than $4.65 \%$ and $26.08 \%$ recorded by Shrestha (2015) and Lama et al. (2015) respectively. High worm load may cause growth retardation, anemia and hemorrhagic diarrhea (Hale and Stewart 1979).

Crenosoma spp. is the Metastrongylus lungworm infecting wild and domesticated canids in Europe (Morgan et al. 2005, Traversa et al. 2010). Recently, emergence of this parasite was observed in several European countries (Traversa et al. 2010) due to population increase and urbanization of Red foxes (Vulpes vulpes) (Deplazes et al. 2004) which is the major reservoir hosts of this parasite in Europe. The prevalence of Crenosoma was found $42.85 \%$ in Red Panda which was almost similar $34.88 \%$ by Shrestha 2015 from Rara National Park, Mugu, Nepal and higher than 4.3\% from European zoos (Bertelsen et al. 2010). Hook Worm infection has been reported from Red Panda of RNP (Shrestha 2015) with prevalence rate $44.19 \%$ which was almost similar with present study which revealed $35.7 \%$. Hookworms are cosmopolitan in distribution (Bowman et al. 2003) and can be transmitted orally but also by cutaneous penetration and cause high mortality in animals and human (Hotez et al. 2004).

Angiostrongylus vasorum was recorded in Red Panda from different countries. It is a most important lungworm which causes pathogenic pneumonia to Red Panda. A. vasorum was recorded from Denmark, U.K and European zoos by Bolt et al.(1992), Janet et al. (2009), Bertelsen et al. (2010) respectively. Angiostrongylus sp. was also reported in Nepal (Lama et al. 2015 and Shrestha 2015) but during this study A. vasorum was not recorded. Aelurostrongyloid spp. have been reported in carnivora by different researchers in global and national context. In the present study, none of these nematodes were isolated in the faecal matter of Red Panda of Illam community forest, Nepal.

Among 14 samples, multiple infection was found to be highest $(78.57 \%)$ in Red Panda followed by double (21.42\%) which was similar with Shrestha (2015). No single infection was observed during study. The intensity of different parasites in Red Panda of Illam community forest were observed in this study. According to result maximum number of Red Pandas were found to be infected with light infection. Some of the faecal samples of Red Panda found to be positive for heavy infection by Eimeria, Oxyuris, Trichostrongylus and Baylisascaris. The heavy infection indicates symptomatic condition causing serious diseases in Red Panda. In general, the parasitic burden in Red panda of Community forest of Illam showed very high posing an important conservation threat.

\section{Acknowledgements}

We are greatly thankful to all the person who helped to complete this study and sincere thanks to

RHF for their financial support.

\section{References}

Adams, J.H., Levine, N.D. and Todd, K.S. 1981. Eimeria and Sarcocystis in raccoons in Illinois. Journal of Protozoology 28(2): 221-222.

Barrett, H.P. and Yarbrough, N. 1921. A method for the cultivation of Balantidium coli. Animal Jurnal Tropical Medicine 1: 161-165.

Barutzki, D. and Schaper, R. 2009. Natural Infections of Angiostrongylus vasorum and Crenosoma vulpis in Dogs in Germany (2007-2009). Researchgate 105: 39-48.

Nepalese Journal of Zoology | Online Volume 3 Issue 1 | November 2015 | Page 54 
Bauer, C. 2011. Baylisascariosis (BaylisBalyascaris procyonis) - a rare parasitic zoonosis in Europe? Berl. Munch. Tierarztl. Wochenschr 124 (11-12): 465-472.

Bertelsen, M.F., Smith, M.F., Willesen, J.L., Jefferies, R., Morgan, E.R. and Monrad, J. 2010. Diversity and prevalence of metastrongyloid nematodes infecting the Red Panda (Ailurus fulgens) in European zoos. Veterinary Parasitology 172: 299-304.

Bhir, T.P. 1998. Crenosoma vulpir and the domestic dog : A study of prevalence on prince Edwared Island and of new diagnostic approaches. MSc Thesis. Department of Pathology and Microbiology, University of Prince Edward Island, Canada.

Bolt, G., Monrad, J., Henriksen, P., Dietz, H.H., Koch, J., Bindseil, E. et al. 1992. The Fox (Vulpes vulpes) as a reservoir for canine angiostrongylosis in Denmark. Field survey and experimental infections. Acta Veterinaria Scandinavica 33: 357-362.

Bowman, D.D., Rock, T., Heaney, K., Neumann, N.R., Ulrich, M. and Amodie, D. 2003. Persistent efficacy of moxidectin canine sustained-releaseinjectable against experimental infections of Ancylostoma caninumand Uncinaria stenocephala in dogs. Veterinary. Therapy 4: 228-233.

Brianti, E., Gaglio, G., Giannetto, S., Annoscia, G., Latrofa, M. S., Torres, F.D. 2012. Troglostrongylus brevior and Troglostrongylus subcrenatus (Strongylida: Crenosomatidae) as agents of broncho-pulmonary infestation in domestic cats. Parasites and vectors 5(178):1-12.

Chaudhary, R.B. 2014. Gastrointestinal parasites in Krisnasar (Antillope cervicapra) of Blackbuck conservation area, Bardiya and Suklaphanta Wildlif Reserve, Kanchanpur. M.sc. Thesis. Central Department of Zoology, Tribhuwan University, Kritipur, Kathmandu, Nepal.

Chavez, D.J., LeVan, I.K., Miller, M.W. and Ballweber, L.R. 2012. BaylisBalyascaris procyonis in raccoons (Procyon lotor) from eastern Colorado, an area of undefined prevalence. Veterinary Parasitology 185: 330-334.

Choudhury, A. 2001. An overview of the status and conservation of the Red Panda (Ailuru sfulgens) in India, with reference to its global status. Oryx 35: 250-259.

Deplazes, P., Hegglin, D., Gloor, S. and Romig, T., 2004. Wilderness in the city :the urbanization of Echinococcus multilocularis. Trends Parasitology 20: 77-84.

Dorji, S., Rajaratnam, R. and Vernes, K. 2012. The Vulnerable red panda Ailurusfulgens in Bhutan: distribution, conservation status and management recommendations. Oryx 46: 536-543.

Dubey, J.P., Garner, M.M., Rosenthal, B.M.. and DeGhetto, D. 2000. Clinical Coccidiosis in Raccoons (Procyon lotor). Journal of Parasitology 86(6): 1299-1303.

Foster, G.W., McCleery, R.A. and Forrester, D.J. 2004. Intestinal Coccidia of Raccoons (Procyon lotor) from Key Largo, Florida, U.S.A. Comparative Parasitology 71(2): 175-177.

Gross, S.J., Ryan, W.G. and Ploeger, H.W. (1999), Anthelmintic treatment of adult dairy cows and the effect on milk production. Veterinary Journal 144: 125-137.

Hale, O.M. and Stewart, T.B. 1979. Influence of an experimental infection of Trichuris suis on performance of pigs. Journal of animal science 49: 1000-1005.

Nepalese Journal of Zoology | Online Volume 3 Issue 1 | November 2015 | Page 55 
Hansen, J. and Perry, T. 1994. The epidemology, Diagnosis and Control of Helminth Parasites of Ruminants, 2nd ed., International Laboratory for Research on Animal Diseases (ILRAD).Nairobi, Kenya. pp. 80-92.

Hernandez, S.M., Galbreath, B., Riddle, D.F., Moore, A.P., Palamar, M.B. and Levy, M.G. 2012. BaylisBalyascaris procyonis in raccoons (Procyon lotor) from North Carolina and current status of the parasite in the USA. Parasitology Research 112(2): 693-698.

Hotez, P.J., Brooker, S., Bethony, J.M., Bottazzi, M.E., Loukas, A. and Xiao, S. 2004. Hookworm infection. National English Journal of Medicine 351: 799-807.

Iwaki, T., Okada, T., Seki, K., Izawa, K. and Sakurai, F. 2012. Ogmocotyle ailuri (Price, 1954) (Digenea: Notocotylidae) Found in the Japanese Monkey, Macaca fuscata. Journal of Veterinary Medical Science 74(9): 1211-1212.

Janet, C.P.K., Lynda, M.G., Jefferies, R., Morgan, E.R., Nanny, W. and Sharon P.R. 2009. Pneumonia from Angiostrongylus vasorum infection in a red panda (Ailurus fulgens fulgens). Journal of Veterinary Diagnosis Investigation 21:270-273.

Kazacos, K.R. 2001. BaylisBalyascaris procyonis and related species. In: Parasitic diseases of wild mammals. Samuels, W.M.; Pybus, M.J. and Kocans, A.A. (eds.). Iowa State University Press/Ames, Iowa. pp.: 301-341.

Kelley, S.W. 2010. Heterobilharziasis (Trematoda: Schistosomatidae) in Raccoons (Procyon lotor) of north central Texas. The Texas Journal of Science 62(1). 75-84.

Kelley, S.W. and Horner, N.V. 2008. The prevalence of cestodes in raccoons (Procyon lotor) from north central Texas. Comparative Parasitology 75: 292-298.

Lama, S.T., Lama, R.P., Regmi, G.R. and Ghimire, T.R. (2015). Prevalence of intestinal parasitic infections in free-ranging Red Panda Ailurus fulgens Cuvier, 1825 (Mammalia: Carnivora: Ailuridae) in Nepal. Journal of Threatened Taxa, 7(8): 7460-7464.

Long, D.B., Campbell, T.A. and Henke, S.E. 2006. BaylisBalyascaris procyonis (Nematoda: Ascaridoidea) in raccoon (Procyon lotor) from Duval County. Texas Journal of Sciences 58(3): 281-285.

Martinez, M.A.J, Cano, E.V. and Rois, J.L. 2015. BaylisBalyascaris procyonis larva migrans in two white-headed lemurs (Eulemur albifrons) in Spain and response to treatment derived from a human pediatric protocol. Veterinary Parasitology 210: 246-249.

Morgan, E.R., Shaw, S.E., Brennan, S.F., De Waal, T.D., Jones, B.R., Mulc-ahy, G., 2005. Angiostrongylus vasorum: a real heartbreakers. TrendsParasitology 21: 49-51.

Nakauchi, K. 1999. The Prevalence of Balantidium coli Infection in Fifty-Six Mammalian Species. Journal of Veterinary Medical Science 61(1): 63-65.

Patterson-kane, J.C., Gibbons, L.M., Jefferies, R., Morgan, E.R., Wenzlow, N. and Redrobe, S.P. 2009. Pneumonia from Angiostrongylus vasorum infection in a red panda (Ailurusfulgensfulgens). Journal of Veterinary Diagnostic Investigation 21: 270-273.

Pradhan, S., Saha, G.K., Khan, J.A. 2001b. Ecology of the red panda Ailurusfulgens in the Singhalila National Park, Darjeeling, India. Biological conservation 98, 11-18.

Nepalese Journal of Zoology | Online Volume 3 Issue 1 | November 2015 | Page 56 
Pradhan, S., Sharma, D., Subba, B. and Chettri, V. 2011. Preliminary investigation on the parasites of mammals at Padmaja Naidu Himalayan Zoological Park, Darjeeling. Zoo's Print 26 (8): 11-13.

Price, E.W. 1960. A note on Ogmocotyle ailuri (Price, 1954) (Trematoda: Notocotylidae). Journal of Helminthological Society of Washington 27: 119-121.

Rao, A.T and Acharjyo L.N. (1984). Diagnosis and classification of common diseases of captive animal at Nandan Kanan Zoo in Orissa (India). Indian Journal of Animal Health pp:147-152.

Roberts, M.S., and Gittleman, J.I. 1984. Ailurusfulgens. Mammalian species. 222: 1-8.

Schuster, F.L. and Ramirez, A.L., 2008. Current world status of Balantidium coli. Cliniacal Microbiology 21: $626-638$.

Sharma, H. P., Belant, J. L., and Swenson, J. E. 2014. Effects of livestock on occurrence of the Vulnerable red panda Ailurus fulgens in Rara National Park, Nepal. Oryx 48: 228-231.

Sharma, H.P. and Belant, J.L. 2009. Distribution and observations of Red Pandas (Ailurus fulgens fulgens) in Dhorpatan Hunting Reserve, Nepal. Small Carnivore Conservation 40: 33-35.

Shrestha, C.K. 2015. Gastrointestinal parasites in Red Panda (Aelurus fulgens) of Rara National Park, Mugu, Rasuwa, Nepal. M.sc. Thesis Central Department of Zoology, Tribhuwan University, Kritipur, Kathmandu, Nepal.

Thapa, C. 2013. Prevalence of gastrointestinal parasites of Himalayan Tahr (Hemitragus jemlahicus) and Barking Deer (Muntiacus veginalis) of Rara National Park, M.sc. Thesis.Central Department of Zoology, Tribhuwan University, Kritipur, Kathmandu, Nepal.

Thomas, C. 2002. Extinction, colonization, and metapopulations: environmental tracking by rare species. Conservation biology 8: 373-378.

Traversa, D., Di Cesare, A. and Conboy, G., 2010. Canine and felinecardiopulmonary parasitic nematodes in Europe: emerging and underestimated. Parasites and Vectors 3: 62.

Varadharajan, A. and Kandassamy, A. 2000. A survey of gastrointestinal parasites of wild animals in captivity in the V.O.C. Park and Mini Zoo, Coimbatore, India. Zoos' print journal 15(5): 257-258.

Villeneuve, A. 2013. Laboratoire de parasitologie Faculte de medecine veterinaire Saint-Hyacinthe Les parasites du chien (www. Wikipedia.org).

Walzer, P.D., Healy, G.R., 1982. Balantidiasis. In: Steele, J.H. (Ed.), Handbook Series in Zoonoses. CRC, Press, Inc., Boca Raton, FL, pp. 15-24.

Wang, X., Choudhury, A., Yonzon, P.B., Wozencraft, C. and Than, Z. (2008). Ailurusfulgens. In: IUCN 2012. IUCN Red List of Threatened Species.

Wei, F., Feng, Z., Wang, Z., and Hu, J. 1999. Current distribution, status and conservation of wild red pandas Ailurusfulgens in China. Biological Conservation 89: 285-291.

Yonzon, P.B. 1989. Ecology and conservation of the red panda in the Nepal-Himalayas. Unpublished Ph.D. Dissertation. University of Maine. Orono, U.S.A.

Yonzon, P.B. 2000. Opportunistic in ecoregion based conservation in Kanchanjunga region Eastern Nepal. In WWF, Kanchanjunga mountain Complex. Biodiversity Assessment and conservation Planing. WWF Nepal Program, Kathmandu, pp: 1-29.

Nepalese Journal of Zoology | Online Volume 3 Issue 1 | November 2015 | Page 57 
Yonzon, P.B. and Hunter, M.L. 1991. Conservation of the red panda Ailurusfulgens. Biological conservation 57: 1-11.

Yonzon, P.B. and Hunter, M.L. 1991b. Cheese, Tourists and Red Pandas in the Nepal Himalayas. Conservation Biology 5(2): 196-202.

Yoshimura, K., Hishinuma, Y. and Sato, M. 1969. Ogmocotyle ailuri (Price, 1954) in the Taiwanese monkey, Macaca cyclopis (Swinhoe, 1862). Journal of Parasitology 55: 460-461.

Zhang, J.S., Daszak, P., Huang, H.L., Guang, Y.Y., Kilpatrick, A. M. and Zhang, S. 2007. Parasite Threat to Panda Conservation. Eco Health Journal Consortium DOI: 10.1007/s10393-007-0139-8

Nepalese Journal of Zoology | Online Volume 3 Issue 1 | November 2015 | Page 58 